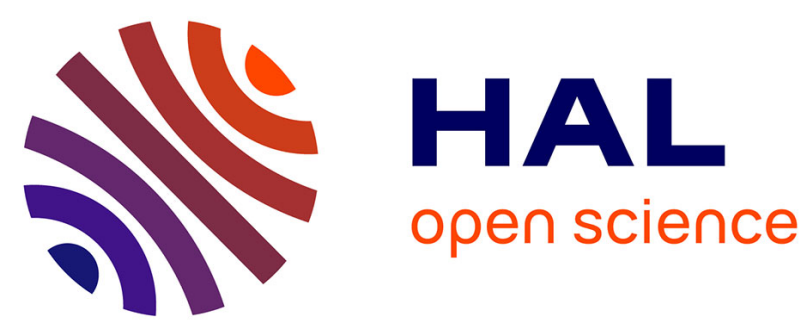

\title{
Predictive coalescence modeling of particles from different polymers: application to PVDF and PMMA pair
}

Sara Aid, Anissa Eddhahak, Zaida Ortega, Daniel Froelich, Abbas Tcharkhtchi

\section{- To cite this version:}

Sara Aid, Anissa Eddhahak, Zaida Ortega, Daniel Froelich, Abbas Tcharkhtchi. Predictive coalescence modeling of particles from different polymers: application to PVDF and PMMA pair. Journal of Materials Science, 2017, 52 (19), pp.11725-11736. 10.1007/s10853-017-1302-4 . hal-01652666

\section{HAL Id: hal-01652666 https://hal.science/hal-01652666}

Submitted on 30 Nov 2017

HAL is a multi-disciplinary open access archive for the deposit and dissemination of scientific research documents, whether they are published or not. The documents may come from teaching and research institutions in France or abroad, or from public or private research centers.
L'archive ouverte pluridisciplinaire HAL, est destinée au dépôt et à la diffusion de documents scientifiques de niveau recherche, publiés ou non, émanant des établissements d'enseignement et de recherche français ou étrangers, des laboratoires publics ou privés. 


\title{
Predictive coalescence modeling of particles from different polymers: application to PVDF and PMMA pair
}

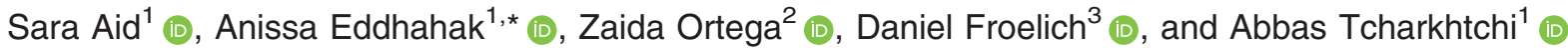 \\ ${ }^{7}$ PIMM Laboratory, CNRS UMR 8006, Arts et Métiers ParisTech, 151 bd de l'Hôpital, 75013 Paris, France \\ ${ }^{2}$ ULPGC, Calle Juan de Quesada, 35001 Las Palmas de Gran Canaria, Las Palmas, Spain \\ ${ }^{3}$ Arts et Métiers ParisTech, Savoie Technolac, rue du Lac Majeur, 73375 Le Bourget du Lac Cedex-Chambéry, France
}

\begin{abstract}
This paper aims to study the coalescence phenomenon of two different polymers PVDF and PMMA. The paper is divided in two parts: the first part is devoted to the experimental work, and the second one focuses on the modeling of the coalescence phenomenon. The first step was a physicochemical and rheological characterization. Then, the coalescence tests have been performed on droplets derived from PVDF and PMMA polymers using a polarized light optical microscope combined with a hot stage. The effect of several significant parameters like temperature and particle size was investigated. The second part of this study is focused on the modeling of the coalescence phenomenon based on the well-known Bellehumeur model. The latter has been commonly used to describe the coalescence phenomenon between identical grains. The novelty of the present work consists in the extension of the coalescence model to wider describe the coalescence phenomenon between grains of different polymers. In addition, probabilistic analysis was performed in order to investigate the effect of the parameters governing the coalescence model, namely the viscosity, the surface tension and the relaxation time. The results have shown a good compromise between the experimental results and the predictive generalized Bellehumeur model.
\end{abstract}

\section{Introduction}

The coalescence is a phenomenon by which two particles of molten polymer meet, producing a homogenous melt [1, 2]. In fact, once two grains in contact reach the melting point, an interface (called the neck) is formed; this interface spreads progressively until stabilization, reaching an overall combination of both polymers, getting a single drop of polymer [3]. In the literature, many works have been devoted to the study of the coalescence phenomenon between polymer particles from experimental and

Address correspondence to E-mail: anissa.eddhahak@ensam.eu 
modeling points of view [4-7]. The modeling of coalescence and especially the prediction of its kinetic rate is a crucial task which governs the early stages of polymer processing. The latter was highlighted by many researchers as a significant parameter which controls the final properties of manufactured materials [8].

The most relevant developed models are often based on the Frenkel theory [9]. Kuczynski et al. [5] studied the sintering behavior of PMMA, founding that the predominant mechanism responsible of the sintering process is related to the non-Newtonian viscous flow. They have reported a temperature dependence of the flow type in the coalescence system: a pseudo-plastic flow at low temperature and a dilatancy one at high temperature. Rosenzweig and Narkis [10] proposed a quantitative model for the prediction of the dimensional variations of two spherical polymer particles. The same authors suggested the hot-stage microscopy method for studying the sintering process of two identical particles or more [5-7, 10, 11]. Bellehumeur proposed a model for the coalescence between identical grains of polymer in a Newtonian and viscoelastic fluid [3, 11]. Unlike to Frenkel model, Bellehumeur approach takes into account the variation of the initial particle radius during the coalescence process. The Bellehumeur model has used the upper-convected Maxwell model (UCMM), supposing a quasi-steady-state flow, to get a nonlinear differential equation [12]. The author assumed that the energy dissipated by viscous flow is in equilibrium with the energy necessary for the tension surface reduction. Therefore, based on this energy balance, the rate of coalescence of two identical particles can be numerically computed and is dependent on the polymer relaxation time, the viscosity, the initial particle size and the surface tension. More recently, the Bellehumeur model is modified to take into account the effect of neighboring grains on the coalescence of two grains in contact $[13,14]$.

These models are, however, restricted to the description of coalescence occurring between identical grains. In the prospect of developing new materials by recycling the waste electric and electronic equipment (WEEE), for instance, mixing two or more different polymers together can be expected. Prior to this, one has to check the compatibility degree between the associated polymers in order to ensure a good quality control of the polymer blend.
In this context, this work aims to study the coalescence of two different polymer grains, the polyvinylidene fluoride (PVDF) and the polymethyl methacrylate (PMMA). The effect of several significant parameters (temperature and particle size) has been studied. A generalized Bellehumeur model is proposed in order to describe the coalescence of polymers particles exhibiting different physical and rheological properties.

\section{Materials and methods}

\section{Materials description}

The experiments were performed using the following polymers; the polyvinylidene fluoride (PVDF), a semi-crystalline thermoplastic polymer supplied by SOLVAY Company and the polymethyl methacrylate (PMMA), an amorphous polymer supplied by ARKEMA Company.

Both polymers were supplied in pellets form. In order to proceed to the coalescence test, these pellets were ground using a grinder (Pulverisette Fritsch). Then, a vibrating sieve was used to determine the particle size distribution. It has been found that the grains size was comprised between 100 and $700 \mu \mathrm{m}$.

Table 1 summarizes some characteristics of the studied polymers.

\section{Experimental characterization}

Different characterization methods were used in order to gather the necessary parameters required for the modeling part.

\section{Rheological tests}

Viscosity measurements were carried out using a rheometer MCR 502 from Anton Paar. The tests were performed at different temperatures under nitrogen atmosphere, in a plate-plate configuration with a gap of $1 \mathrm{~mm}$. Two types of measurements were carried

Table 1 Characteristics of the studied polymers

\begin{tabular}{llll}
\hline Polymers & $T_{\mathrm{g}}\left({ }^{\circ} \mathrm{C}\right)$ & $T_{\mathrm{f}}\left({ }^{\circ} \mathrm{C}\right)$ & Density $(\mathrm{g} / \mathrm{cc})$ \\
\hline PVDF & -40 & 172 & $1.75-1.80$ \\
PMMA & 105 & & 1.19 \\
\hline
\end{tabular}


out: In the first one, the dynamic viscosity of polymers was followed versus the shear rates, whereas the second one focused on the determination of polymers relaxation time by evaluating the viscous and elastic response of the complex viscosity within a frequency range from 0.1 to $100 \mathrm{~Hz}$ by considering an imposed strain of $0.1 \%$.

\section{Surface tension measurements}

The surface tension of the polymers was determined by the hanging drop method using DIGIDROP GBX device. The pendant drop measurement is usually performed by suspending a small drop of the studied liquid (polymers in molten state) from the nozzle of the end of a vertical tube of a radius $r$ (Fig. 1) mounted in a thermostat chamber. Using a special camera with a fixed image distance and a telecentric lens system, the shape and the size of the drop can be determined by a few measurements on a large image [15]. Based on the equations describing the equilibrium of the drop, the limit tension of the liquid can be calculated from several measurements made on an image of a hanging drop. The DIGIDROP GBX apparatus used to measure the surface tension of the polymers is equipped with Visio drop software to calculate the surface tension denoted $(\sigma)$ using the following equations:

$\sigma=\frac{\left(\rho_{1}-\rho_{\mathrm{v}}\right) g d_{\mathrm{e}}^{2}}{H}$

where $H$ is a tabulated parameter depending on the diameter ratio denoted $S$ given by the following expression: $S=\frac{d_{\mathrm{s}}}{d_{\mathrm{e}}}$, where $d_{\mathrm{e}}$ is the equatorial

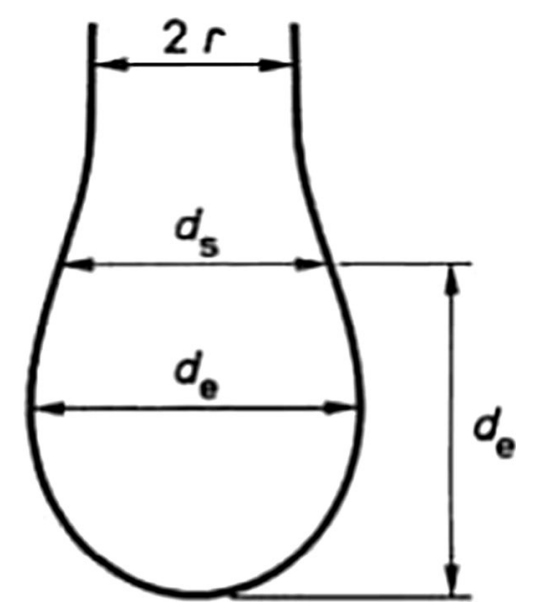

Figure 1 Profile of a pendant drop [16]. diameter, $d_{\mathrm{s}}$ is the diameter in the horizontal plane located at the distance $d_{\mathrm{e}}$ from the base, $\rho_{1}$ and $\rho_{\mathrm{v}}$ represent, respectively, the liquid and the air density, and $g$ is the gravity acceleration.

Experiments were carried out at the same temperature as the coalescence tests under nitrogen atmosphere to avoid the polymers oxidation.

\section{Coalescence tests and parameters effect}

The coalescence experiments were performed with a polarized light microscope (BH-2 from OLYMPUS) combined with a hot-stage instrument (from Linkam) driven by the LinkSys 32 software, a video camera and a video capture software (Fig. 2). The tests have been performed according to a laboratory protocol. At the beginning, the polymer powder was spread on the platinum glass and two grains of PVDF/PMMA pair were selected. It shall be noted that the initial shape of powder particles is very heterogeneous and irregular. Consequently, in order to obtain an ideally experimental configuration for the coalescence test, the powder grains were preheated up to their melting point to smooth their shapes and making them as spherical as possible.

After that, the grains were cooled down and put in contact. A thermal set program is imposed by setting the heating rate $\left(10{ }^{\circ} \mathrm{C} / \mathrm{min}\right)$ until $5{ }^{\circ} \mathrm{C}$ below the coalescence temperature; then the heating is stopped, and an isothermal condition is established to initiate the coalescence. At this stage, the images acquisition conditions are set and the test starts. The obtained images are analyzed using image analysis software in order to measure the neck (interface) formed between the grains at different time intervals.

Furthermore, a parametric investigation was undertaken in order to identify the most relevant significant parameters on the coalescence kinetic of PVDF/PMMA pair.

To study the effect of temperature, the particle size of both polymers was fixed to $400 \mu \mathrm{m}$ and the tests were performed at different temperatures (210, 220 and $230{ }^{\circ} \mathrm{C}$ ). Besides, in order to analyze the effects of the grain size, three experimental configurations of the isothermal coalescence (at $220^{\circ} \mathrm{C}$ ) tests were considered: (1) similar size, (2) PVDF bigger than PMMA and (3) PMMA bigger than PVDF as specified below:

1. PMMA $500 \mu \mathrm{m}$, PVDF $510 \mu \mathrm{m}$. 


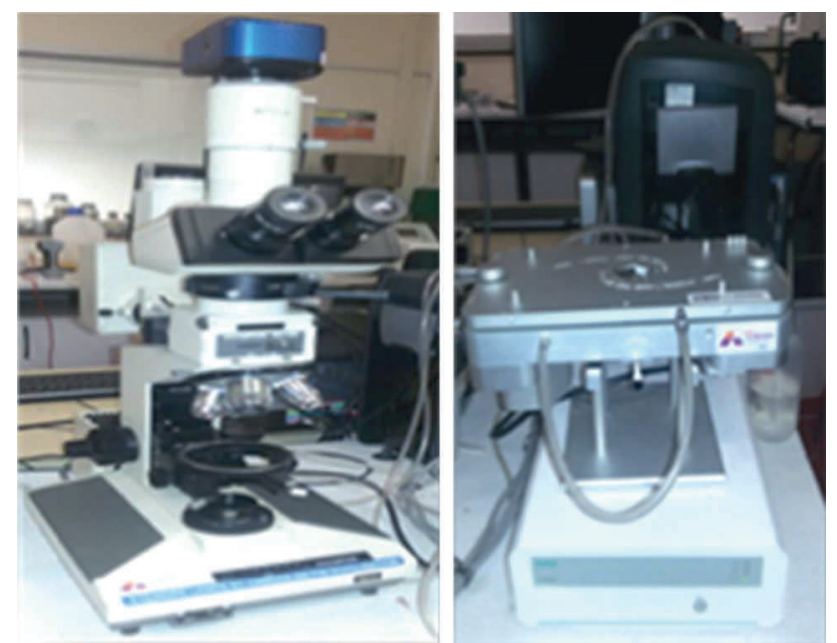

Figure 2 Apparatus used for the coalescence experiment: optical microscopy (left) and hot-stage instrument (right) used for coalescence test.

2. PMMA $500 \mu \mathrm{m}$, PVDF $870 \mu \mathrm{m}$.

3. PMMA $850 \mu \mathrm{m}$, PVDF $330 \mu \mathrm{m}$.

\section{Theoretical background and coalescence modeling}

The coalescence is a process driven by the surface tension and counteracted by the viscous dissipation associated with the molecular diffusion within the coalescing domain. The Bellehumeur model is based on the balance between the work of surface tension, on the one hand and the viscous dissipation, on the other one. Besides, the variation versus time of the particle radius during the coalescence process is considered [3, 11].

The work of viscous forces is expressed according to the following equation:

$w_{\mathrm{v}}=\iiint_{V}(\tau: D) \mathrm{d} V$

where $V$ is the volume of the coalescence system, $\tau$ and $D$ are, respectively, the stress and the deformation tensors.

To take into account the viscoelastic behavior in the description of the coalescence phenomenon, Bellehumeur used the upper-convected Maxwell constitutive equation [3] given by:

$\lambda \frac{\partial \tau}{\partial t}+\tau=2 \eta D$ where $\lambda$ denotes the relaxation time and $\frac{\partial \tau}{\partial t}$ is a general form of the invariant derivative of the extra-stress tensor.

By assuming an extensional flow field, the development of Eq. (2) using the relation (3) leads to the dissipated energy equation expressed as following:

$W_{\mathrm{v}}=\frac{32 \Pi a_{0}{ }^{3} \eta(1-\cos \theta)}{(1+\cos \theta)(1-\cos \theta)^{2}}\left(\theta^{\prime}\right)^{2}$

where $a_{0}$ denotes the initial radius of the grain and $\theta$ the coalescence angle (Fig. 3)

On the other hand, the work of surface tension $W_{\mathrm{s}}$ is defined as:

$W_{s}=-\Gamma \frac{\mathrm{d} S}{\mathrm{~d} t}$

where $\Gamma$ is the coefficient of surface tension and $S$ the surface of the coalescence system. Thus, Eq. (5) can be written as follows:

$W_{\mathrm{s}}=\Gamma \frac{8 \Pi a_{0}^{2} 2^{1 / 3} \cos \theta \sin \theta}{(1+\cos \theta)^{4 / 3}(2-\cos \theta)^{5 / 3}} \theta^{\prime}$

By equating the energy dissipated by the viscous flow (Eq. 4) and that of the surface tension (Eq. 6), a nonlinear differential equation is obtained (Eq. 7) [3].

$8\left(\alpha \lambda K_{1}\right)^{2} \theta^{\prime 2}+\left\{2 \alpha \lambda K_{1}+\frac{\eta a_{0}}{\Gamma} \frac{K_{1}^{2}}{K_{2}}\right\} \theta^{\prime}-1=0$

Where $K_{1}=\frac{\sin \theta}{(1+\cos \theta)(2-\cos \theta)}$

$K_{2}=\frac{2^{\frac{-5}{3}} \cos \theta \sin \theta}{(1+\cos \theta)^{\frac{4}{3}}(2-\cos \theta)^{\frac{5}{3}}}$

where $\eta$ is the viscosity, $\lambda$ is the relaxation time, $a_{0}$ is the initial particle radius, $\alpha$ is the Maxwell coefficient taken equal to 1 in the case of upper-convected Maxwell (UCM), and $\theta$ is the sintering angle given by:

$\sin \theta=\mathrm{X} / r$.

\section{Generalized Bellehumeur model}

As it can be noticed, Eq. (7) leads to the determination of the coalescence angle $(\theta)$ by considering that the grains in the sintering system exhibit similar physical and rheological properties $(\eta, \lambda$ and $\Gamma)$ (grains of the same polymer). In the case of coalescence between two different polymer particles with different properties, one shall take into account the intrinsic characteristics of each polymer involved in 


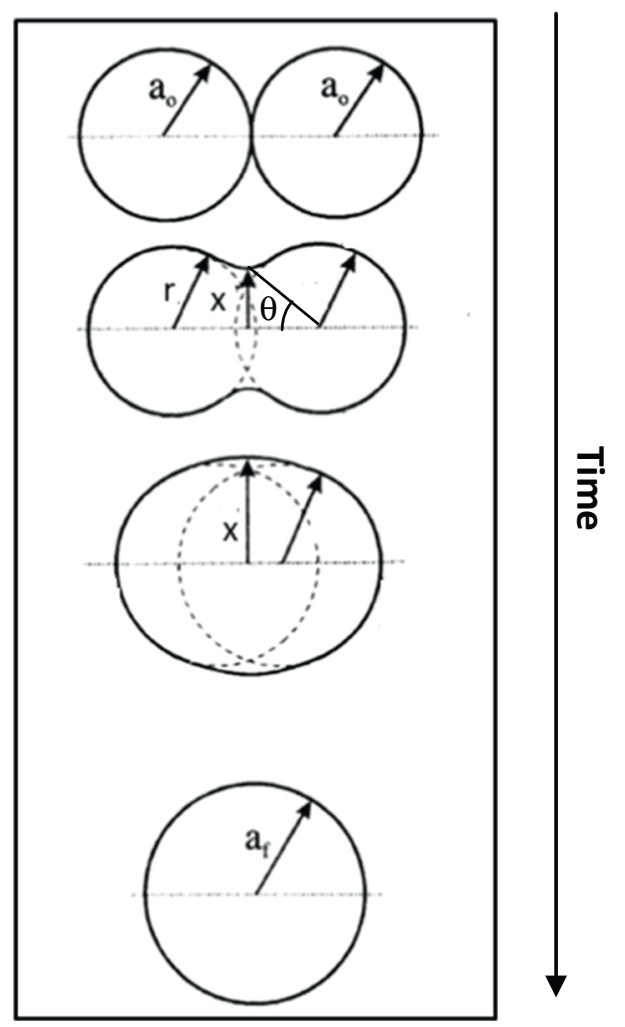

Figure 3 Schematic diagram of the coalescence steps [1].

the sintering domain. Accordingly, the resolution strategy of the coalescence problem shall be modified; instead of solving the Bellehumeur equation, one suggests to solve a system of four equations expressed as:

$$
\left\{\begin{array}{l}
8\left(\bar{\lambda} K_{1} \theta^{\prime}\right)^{2}+\left(2 \bar{\lambda} K_{1}+\frac{\bar{\eta} a_{0}}{\bar{\Gamma}} \frac{K_{1}^{2}}{K_{2}}\right) \theta^{\prime}-1=0 \\
\bar{\eta}=f\left(\eta_{1}, \eta_{2}\right) \\
\bar{\lambda}=g\left(\lambda_{1}, \lambda_{2}\right) \\
\bar{\Gamma}=h\left(\bar{\Gamma}_{1}, \bar{\Gamma}_{2}\right)
\end{array}\right.
$$

The first equation of the above system corresponds to the Bellehumeur model which considers equivalent properties of the two polymers particles involved in the coalescence domain.

where $\bar{\eta}, \bar{\lambda}$ and $\bar{\Gamma}$ are the equivalent properties, respectively, associated with the viscosity, the relaxation time and the surface tension. For the determination of $\bar{\eta}, \bar{\lambda}$ and $\bar{\Gamma}$, a modified mixture law expressed as follows is postulated:

$\bar{\eta}=\frac{\eta_{1}+k_{\eta} \eta_{2}}{1+k_{\eta}}=f\left(\eta_{1}, \eta_{2}\right)$

$$
\begin{aligned}
& \bar{\lambda}=\frac{\lambda_{1}+k_{\lambda} \lambda_{2}}{1+k_{\lambda}}=g\left(\lambda_{1}, \lambda_{2}\right) \\
& \bar{\Gamma}=\frac{\Gamma_{1}+k_{\Gamma} \Gamma_{2}}{1+k_{\Gamma}}=h\left(\Gamma_{1}, \Gamma_{2}\right)
\end{aligned}
$$

where $k_{\eta}, k_{\lambda}$ and $k_{\Gamma}$ are correction factors attributed, respectively, to viscosity, relaxation time and surface tension of the studied polymers. Then to correctly identify the equivalent properties, it is necessary to determine the correction factors such as to minimize the square quadratic error between the predictive model and the experimental data derived from the coalescence tests.

\section{Results and discussion}

\section{Viscosity results}

Figure 4a shows the evolution of viscosity of PVDF and PMMA with the shear rate at $220^{\circ} \mathrm{C}$, whereas Fig. $4 \mathrm{~b}$ presents the Cole-Cole diagram (the real part $\eta^{\prime}$ versus the imaginary part $\eta^{\prime \prime}$ of the complex viscosity). As shown in Fig. 4a, the PVDF polymer exhibits a lower viscosity than the PMMA one. For instance, a viscosity of $4677 \mathrm{~Pa} \mathrm{~s}$ for PVDF versus $14034 \mathrm{~Pa}$ s for PMMA has been obtained at a shear rate equal to $0.01 \mathrm{~s}^{-1}$. At the same temperature, the plots of the real viscosity $\left(\eta^{\prime}\right)$ as function of the imaginary one $\left(\eta^{\prime \prime}\right)$ showed that the relaxation time, deduced from the Cole-Cole curve peak, of PVDF is less important ( $0.16 \mathrm{~s})$ than the PMMA (0.87 s). Note that the relaxation time determined here is one among the other relaxation times which could be experienced by the polymers during its thermo-mechanical history. In addition, this parameter was computed in quasi-static configuration (small deformation of $0.1 \%$ ) and at a constant temperature of $220{ }^{\circ} \mathrm{C}$ to faithfully reproduce the experimental conditions of the isothermal coalescence test.

Table 2 summarizes the results of viscosity at a shear rate of $0.01 \mathrm{~s}^{-1}$ and the time relaxation of both PVDF and PMMA polymers for different temperatures.

\section{Surface tension}

Figure 5 presents the results of the surface tension measurements for both polymers at $220^{\circ} \mathrm{C}$. An important dispersion of this parameter can be 
(a)

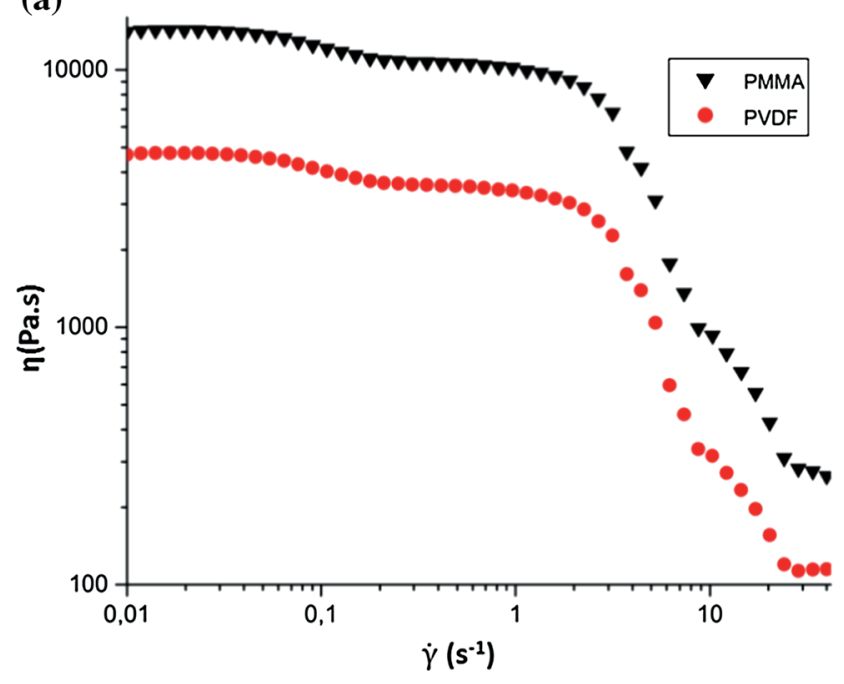

(b)

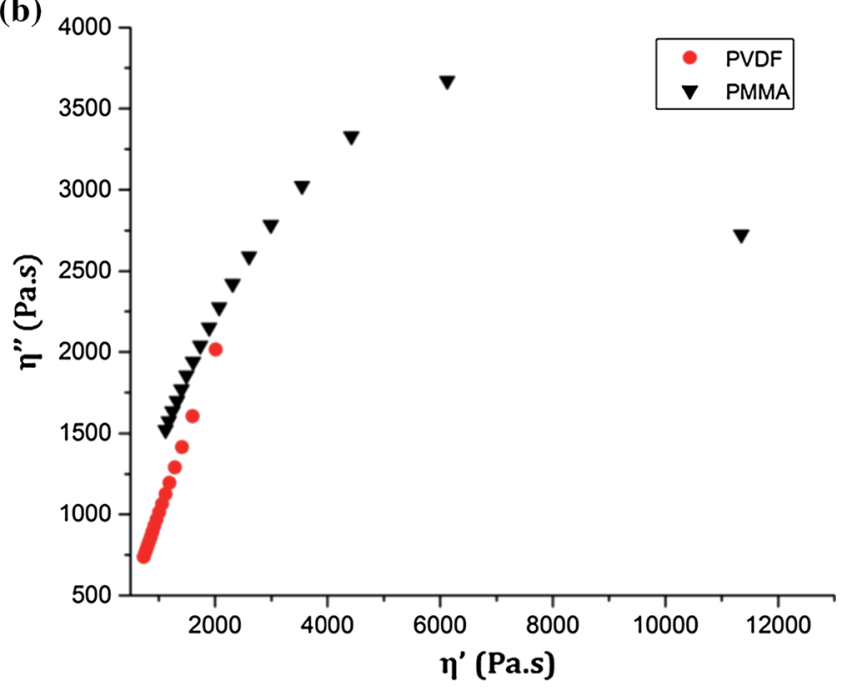

Figure 4 Results of dynamic viscosity (a) and complex viscosity (b) of PVDF and PMMA at $220{ }^{\circ} \mathrm{C}$.

Table 2 Results of viscosity and relaxation time of PVDF and PMMA polymers at different temperatures

\begin{tabular}{llllll}
\hline$T\left({ }^{\circ} \mathrm{C}\right)$ & PVDF & & & PMMA & \\
\cline { 2 - 3 } \cline { 6 - 6 } & $\eta($ Pa s $)$ & $\lambda(\mathrm{s})$ & & $\eta($ Pa s $)$ & $\lambda(\mathrm{s})$ \\
\hline 210 & 2800 & 0.21 & & 29267 & 1.42 \\
220 & 4677 & 0.16 & & 14034 & 0.87 \\
230 & 1774 & 0.12 & & 6473 & 0.56 \\
\hline
\end{tabular}

noticed. This dispersion is due to the experimental uncertainties of the different measurements as well as the test difficulty and repeatability.

\section{Coalescence of PVDF/PMMA and identification of significant parameters}

\section{Temperature effect}

The coalescence is the result of interdiffusion of two molten grains with high molecular mobility. For illustration, an example of images obtained by optical microscopy during coalescence of PVDF/PMMA pair is presented in Fig. 6. The evolution of the interface between these two grains is followed versus time (Fig. 7). As expected, it is clearly observed that the rate of coalescence is significantly impacted by the thermal conditions of the test. This finding can be mainly explained by the direct consequence of temperature on the polymer viscosity which decreases with time, allowing thereby to an easier and faster interdiffusion between the two grains of PVDF and PMMA pair.

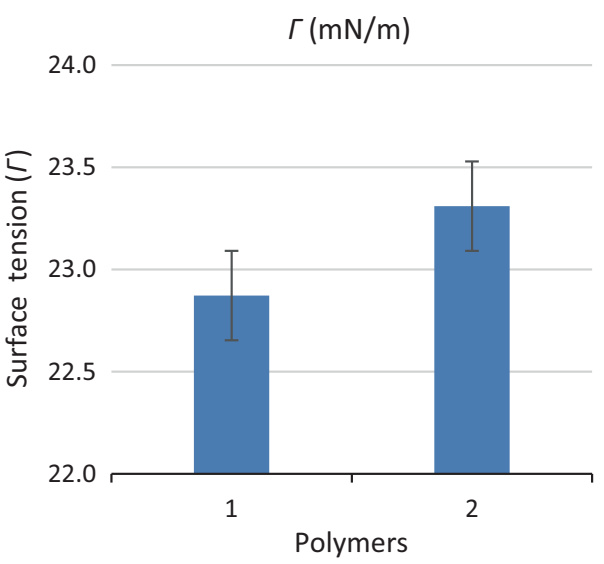

Figure 5 Results of surface tension measurements of PVDF (1) and PMMA (2) polymers at $220^{\circ} \mathrm{C}$.

\section{Grain size effect}

Figure 8 presents the results of the isothermal coalescence tests (at $220^{\circ} \mathrm{C}$ ) of PVDF/PMMA pair with different particle sizes.

Several investigations undertaken to study the coalescence of similar polymer grains indicated that the coalescence kinetic increases by decreasing the grain size. They concluded that this phenomenon is a result of the low thermal conductivity of the polymers. In fact, the bigger is the grain size of the polymer, the more important is the temperature gradient between the center and the grain surface resulting in a slower melting process and thus in a lower coalescence rate. In the present work, the coalescence carried out between two different polymers 


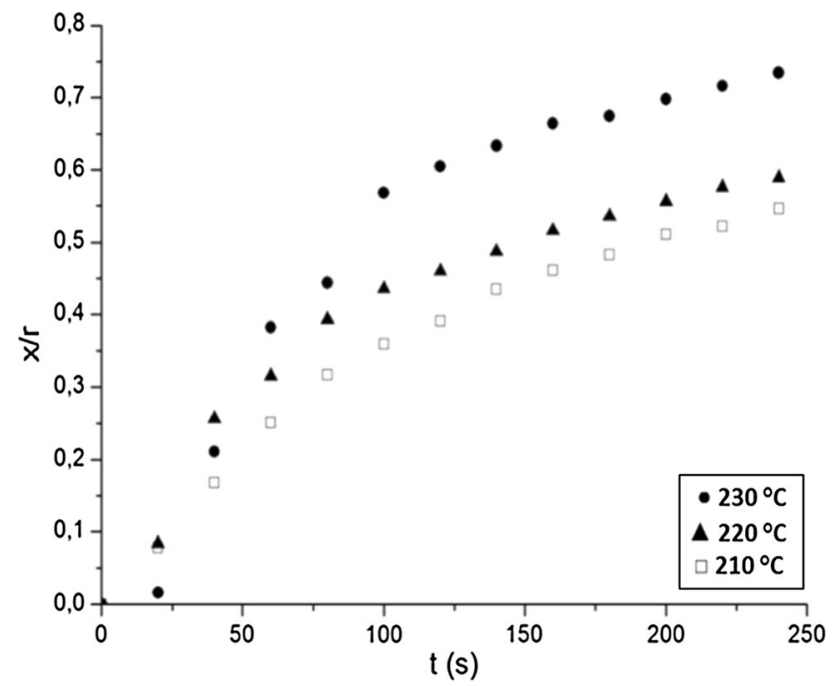

Figure 6 Temperature effect on coalescence rate of $\mathrm{PVDF} /$ PMMA pair $(400 \mu \mathrm{m})$ at 210,220 and $230{ }^{\circ} \mathrm{C}$.

is studied, and therefore, it is of primary importance to determine the extent to which the particle size of each polymer affects the coalescence rate. Figure 8 shows that the coalescence rate between PVDF and PMMA polymers is significantly affected by the PMMA grain size; in fact it increases by decreasing the grain size of the PMMA grain. Considering these results and the zero shear viscosity measurements of the polymers pair at the experiment temperature $\left(220^{\circ} \mathrm{C}\right)$, which indicates that the PMMA is more viscous than PVDF (Table 2), it can be suggested that PMMA flow influences more significantly the kinetics of coalescence than the PVDF one. Indeed, it is

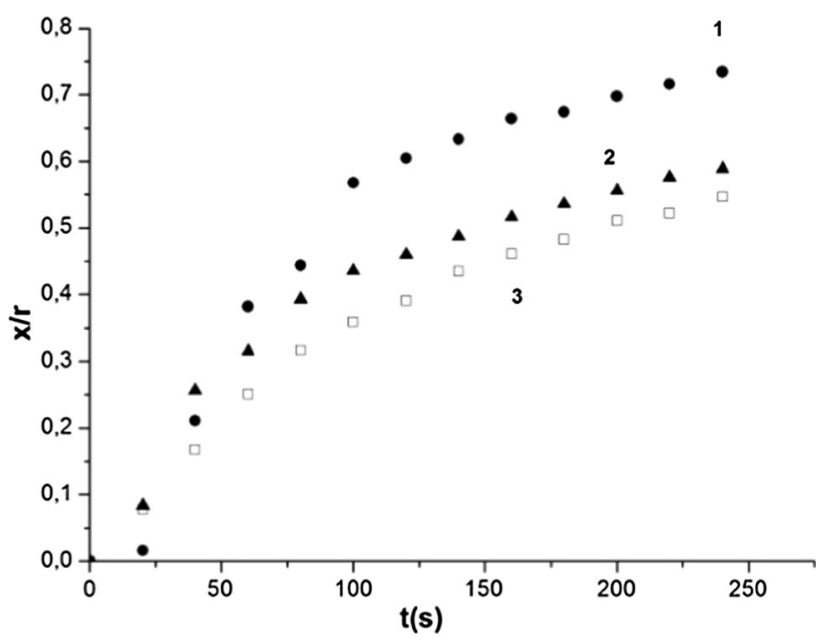

Figure 8 Grain size effect on coalescence rate of PVDF/PMMA pair at $220{ }^{\circ} \mathrm{C}$; (1) PMMA $500 \mu \mathrm{m}$ and PVDF $510 \mu \mathrm{m}$, (2) PMMA $500 \mu \mathrm{m}$ and PVDF $870 \mu \mathrm{m}$, (3) PMMA $850 \mu \mathrm{m}$ and PVDF $330 \mu \mathrm{m}$.

observed that the bigger is the PMMA particle size, the more important is the temperature gradient within the grain, reducing thereby the diffusion rate between the grains.

\section{Predictive model results}

In this section, the results of the generalized Bellehumeur model developed in "Theoretical background and coalescence modeling" section are presented. Figure 9 depicts the numerical results of
Figure 7 Images of coalescence steps of PVDF/ PMMA pair at $220{ }^{\circ} \mathrm{C}$.
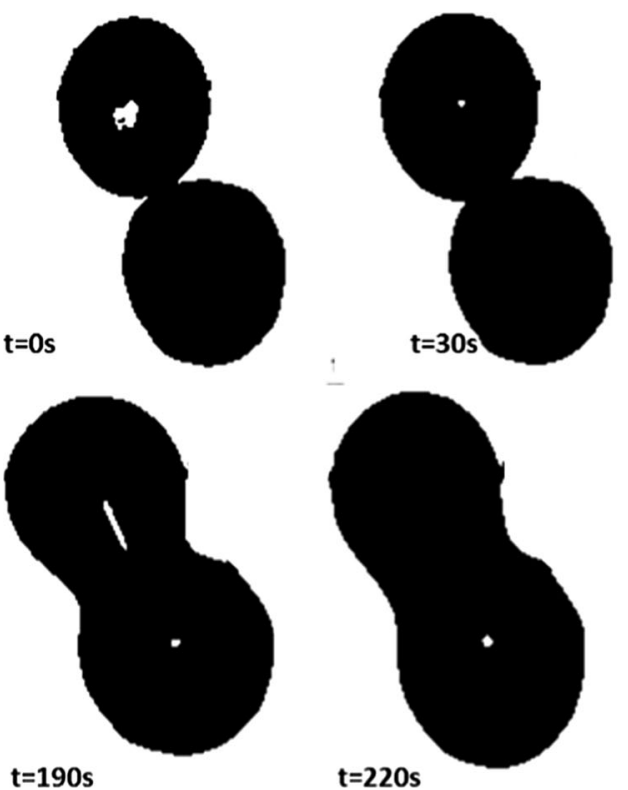

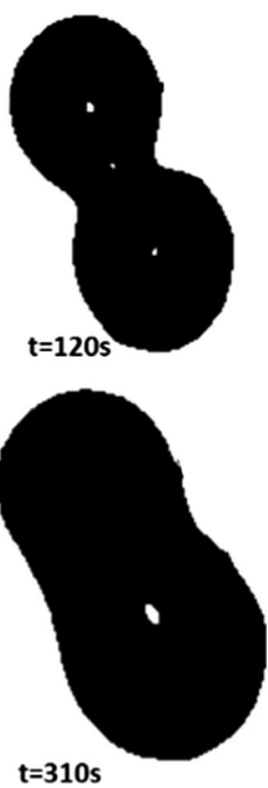




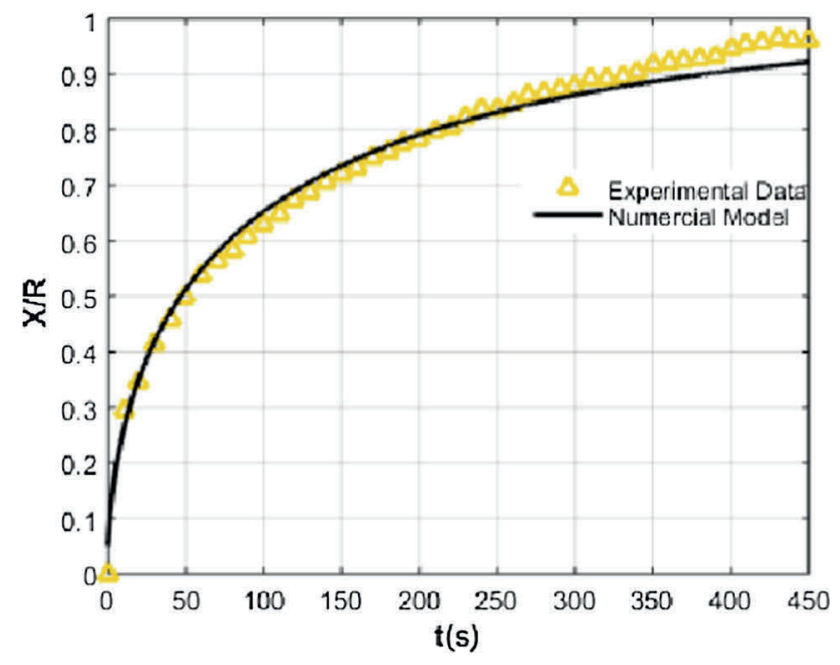

Figure 9 Results of PVDF/PMMA coalescence, comparison with the experimental data $\left(T=220^{\circ} \mathrm{C}, a_{0}=540 \mu \mathrm{m}\right)$.

Table 3 Results of the optimized rheological properties of the coalescence system

\begin{tabular}{lll}
\hline$\eta^{*}($ Pa s $)$ & $\Gamma^{*}(\mathrm{~N} / \mathrm{m})$ & $\lambda^{*}(\mathrm{~s})$ \\
\hline 9727 & 0.0258 & 0.74 \\
\hline
\end{tabular}

PVDF/PMMA coalescence in comparison with the experimental coalescence data recorded at $220^{\circ} \mathrm{C}$.

As can be noticed, the numerical predictive model shows a good agreement with the experimental data. The recorded error was estimated in $2.7 \%$. The numerical resolution of the equations system (11) led to the optimized values of the equivalent rheological parameters $\eta^{*}, \Gamma^{*}$ and $\lambda^{*}$, respectively, for viscosity, surface tension and relaxation time of the coalescence system.

Table 3 summarizes the best fit of the physicorheological values.

\section{Probabilistic parametric study of coalescence}

As mentioned in "Surface tension" section, the results of the surface tension measurements have shown a great dispersion and uncertainties which led to inaccurate estimation of this key parameter. Indeed, it shall be highlighted that the surface tension coefficient plays an important role in coalescence phenomenon since it dictates the attraction force which governs and promotes the coalescence progress. Accordingly, in order to further investigate the surface tension effect on the coalescence modeling, the numerical predictive model was conducted taking into account the uncertainties of this parameter.

For this purpose, the statistical data derived from the numerous experiments (mean and standard deviation) were used to adjust a probability density function (pdf for short) to describe the dispersion of the independent random variable $\Gamma$ associated with the surface tension parameter $\Gamma$. For the surface tension case, the average and dispersion values were set to $0.0258 \mathrm{~N} / \mathrm{m}$ and $20 \%$, respectively. The construction of the pdf was carried out based on the well-known entropy maximum principle. The latter allows the construction of the suitable pdf of a random variable by maximizing the uncertainty (or the entropy) over the potential probability density functions in the light of the available (or used) information, namely the average value, the standard deviation, the support, the higher moment value of the random variable. For further information about this principle, the readers could consult the detailed research works of Jaynes et al. [16].

Accordingly, the identification of the pdf of the random variable $\Gamma$ leads to a Gaussian function as illustrated in Fig. 10.

Figure 10 illustrates the main results of the probabilistic numerical model by taking into account the surface tension parameter uncertainties. The upper curves Fig. 10(a) and (b) show, respectively, the pdf of the random variable $\Gamma$ and the 2000 random trials performed according this pdf. The red continuous line in Fig. 10b represents the average value of the surface tension. The implementation of the random values in the suggested predictive numerical model leads to probabilistic responses of the coalescence evolution versus time as shown in the lower Fig. 10(c) and (d). It can be seen that the coalescence probabilistic responses present a similar tendency and that the data curve (in triangular marker) lies inside the spectrum of the probabilistic responses. The probabilistic numerical predictions are in general in a good agreement with the data. Note that the maximal error recorded between the experimental response and that of the probabilistic model was found to be $6 \%$.

In addition, in order to compare the surface tension effect regarding to the other parameters governing the coalescence predictive model, namely the viscosity, the relaxation time and the grain radius (Eq. 11), similar procedure than previously was followed, varying one parameter while keeping constant the remaining ones. For instance, when the 
(a)

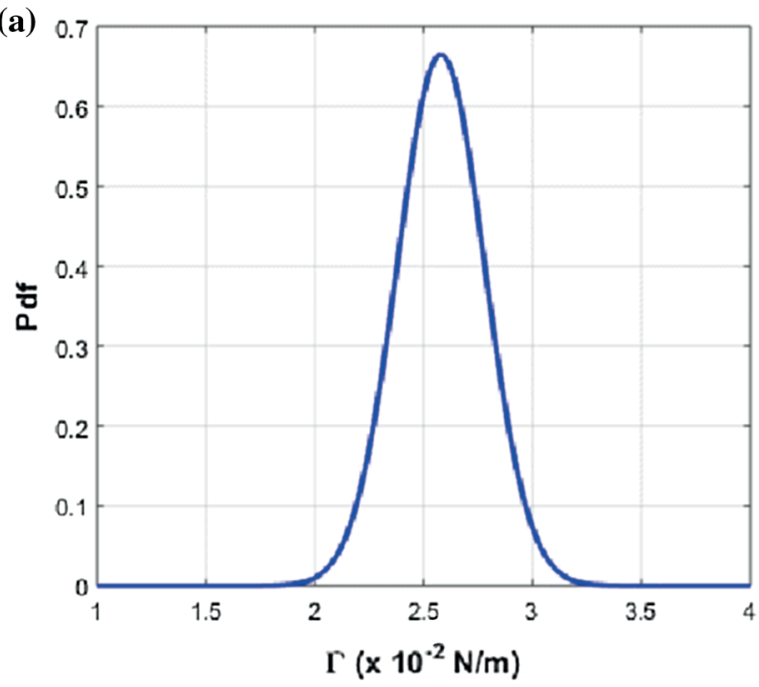

(c)

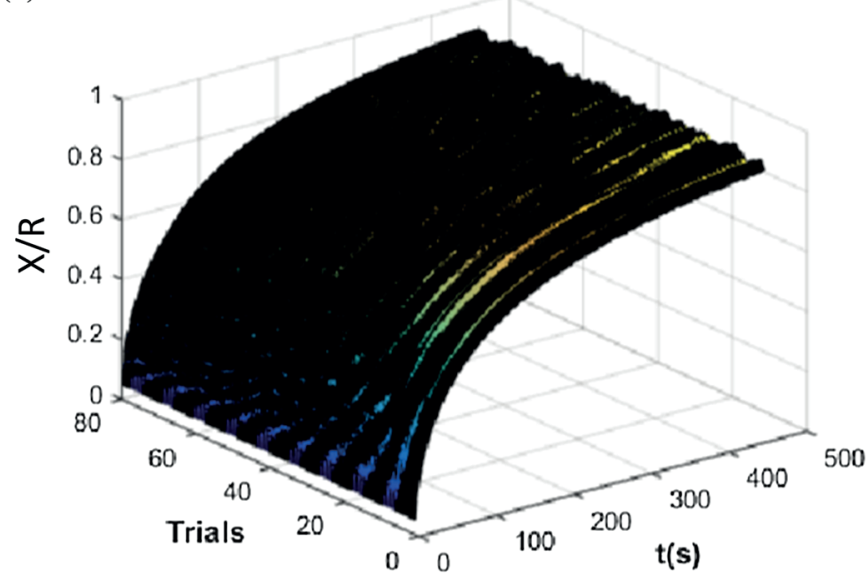

(b)

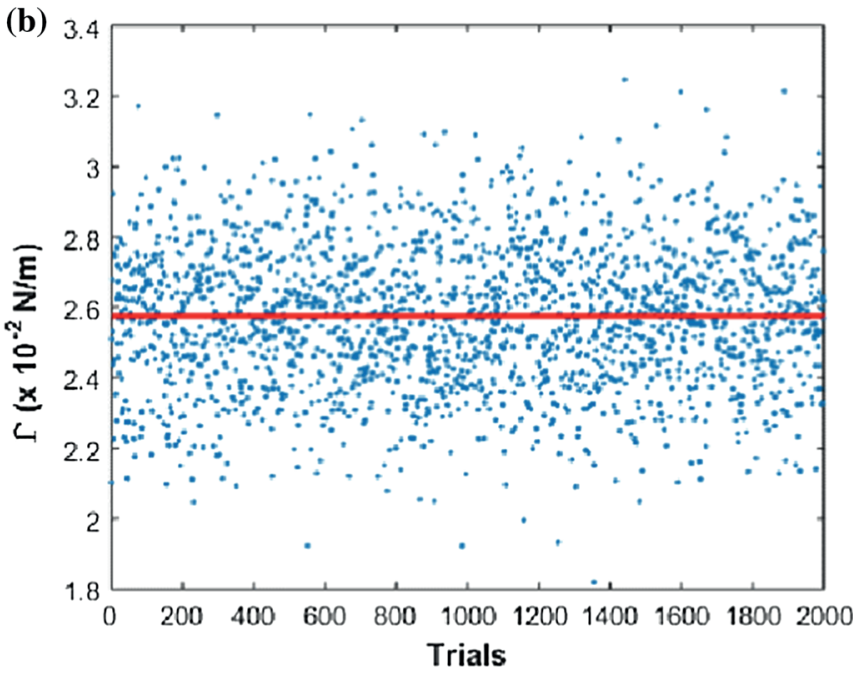

(d)

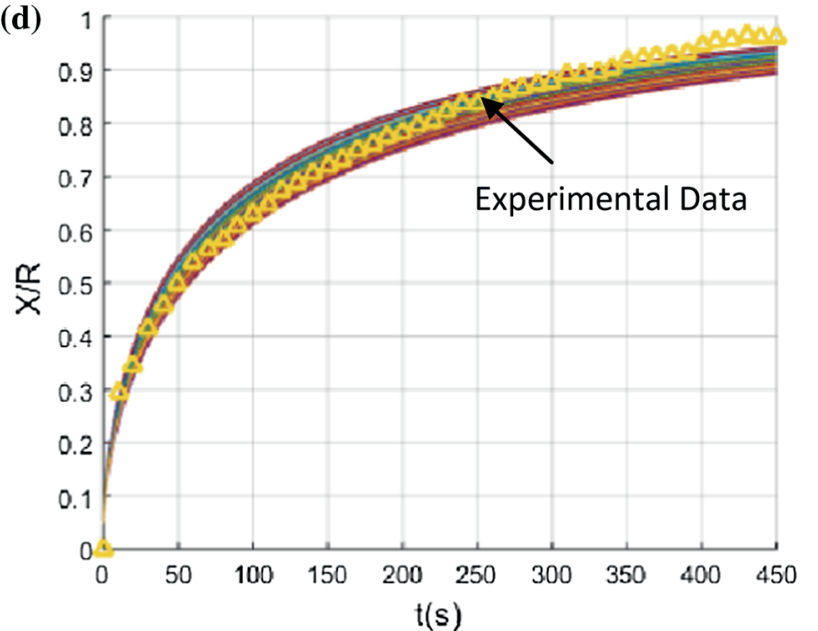

Figure 10 Results of the probabilistic coalescence model: a pdf of the random variable $\boldsymbol{\Gamma}, \mathbf{b}$ random trials of $\boldsymbol{\Gamma}$ according to its pdf, $\mathbf{c}$ random responses of coalescence evolution, $\mathbf{d}$ comparison of the probabilistic responses with the coalescence data (triangular marker).

viscosity is considered as an independent random variable, surface tension and time relaxation were set to their averages values as well as the grain radius parameter $\left(a_{0}=540 \mu \mathrm{m}\right)$. The standard deviation considered is taken equal to $20 \%$ by analogy to the surface tension case, whereas the average values considered for this parametric study are those given in Table 3.

Plots of Fig. 11 present the results of the probabilistic numerical coalescence responses taking into account the dispersion of the governing model parameters. It can be concluded from these graphs that viscosity, surface tension and grain radius are significant parameters which exhibit nearly the same effect on the coalescence response of PVDF/PMMA pair. The relaxation time, however, seems to be a nonsignificant parameter for the coalescence model since all curves nearly superimpose as shown in Fig. 11e. These findings can be explained by the fact that coalescence phenomenon is primarily influenced by polymer viscosity and the surface tension work, whereas the effect of the modulus is less important. The grain radius is also a key parameter in the model which impairs similarly the coalescence phenomenon.

In Fig. 12, the combined effect of viscosity, surface tension and grain radius uncertainties is shown. As expected, the result highlighted a large spectrum of the probabilistic coalescence responses between PVDF and PMMA grains when all the significant parameters are simultaneously subjected to uncertainties. The maximal error recorded between the 
(a)

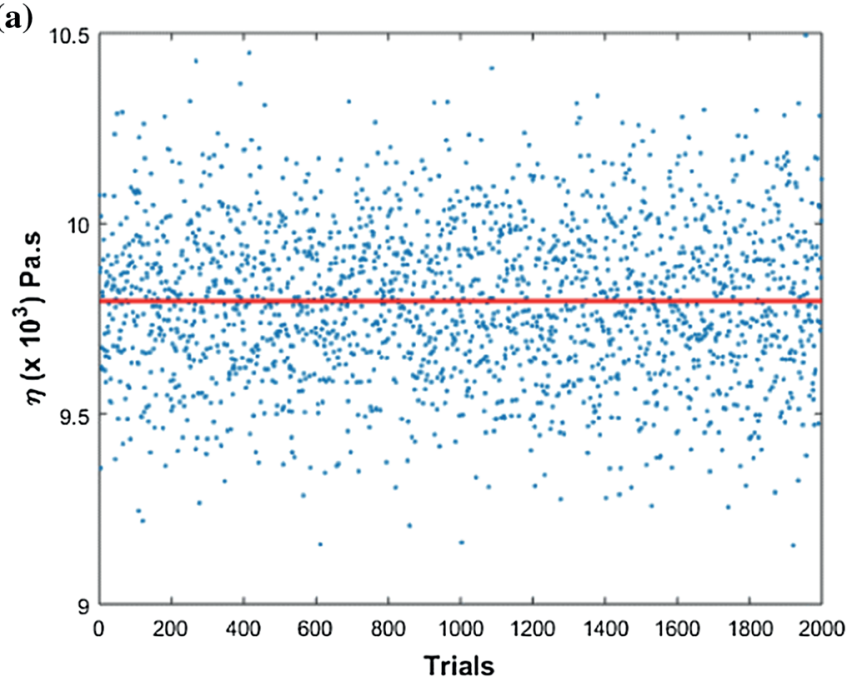

(c)

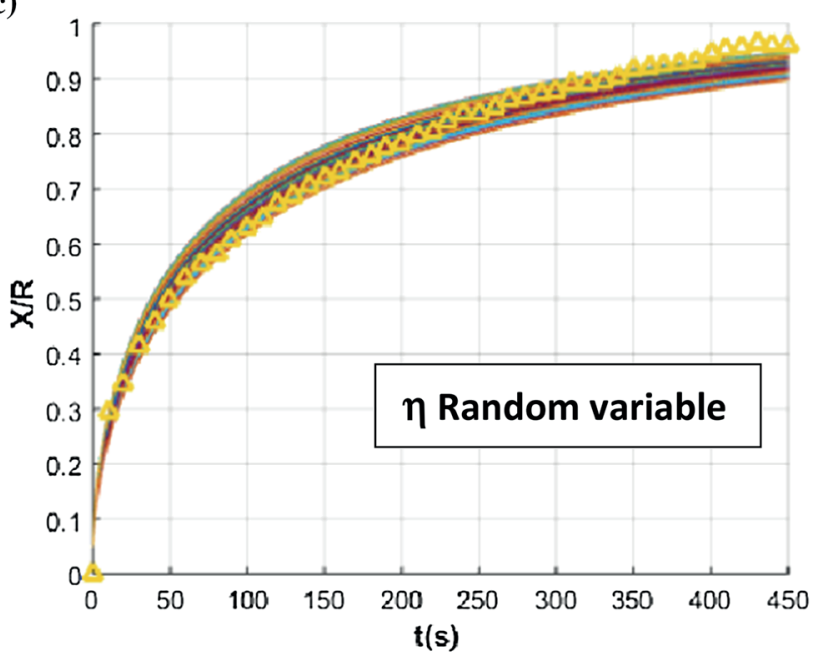

(b)

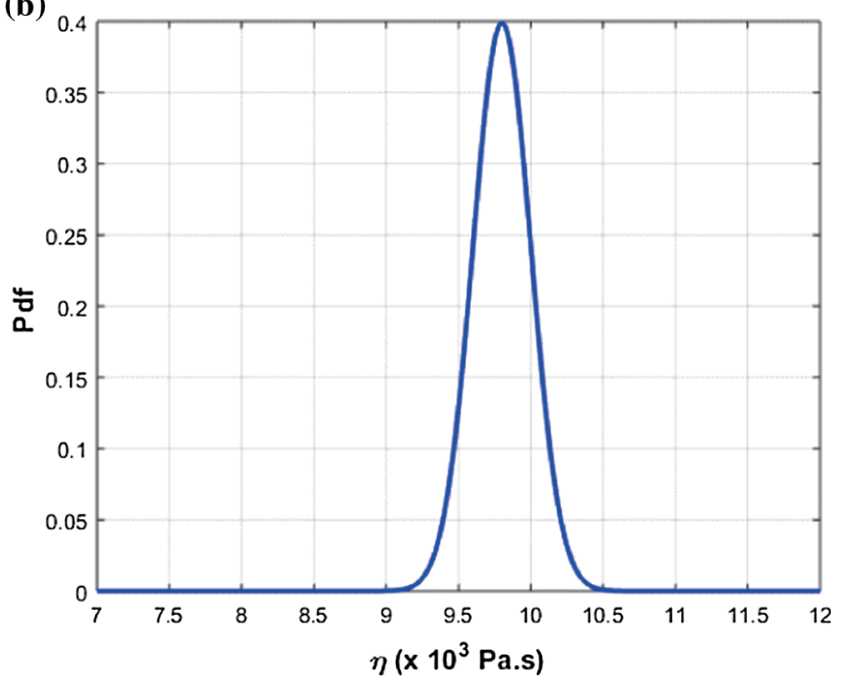

(d)

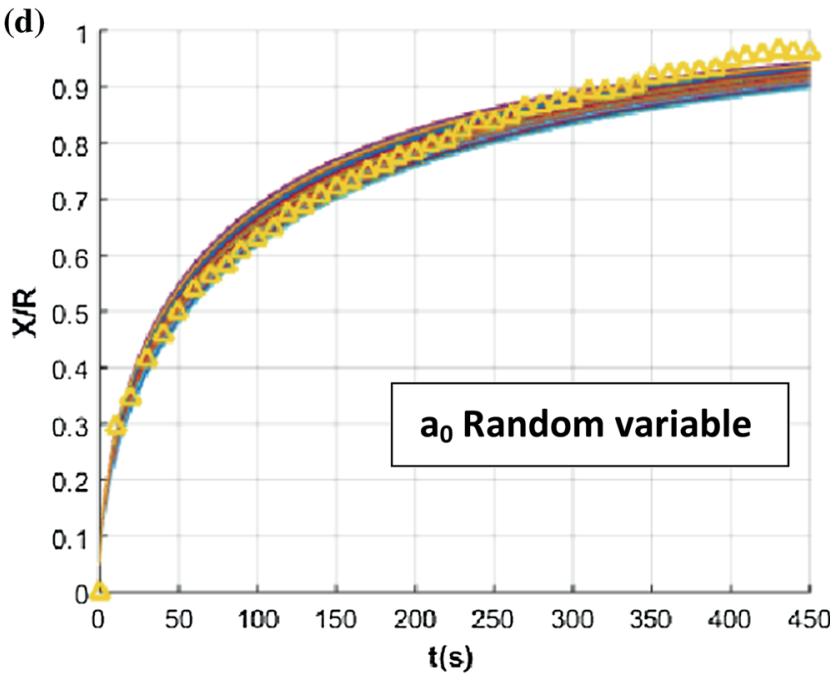

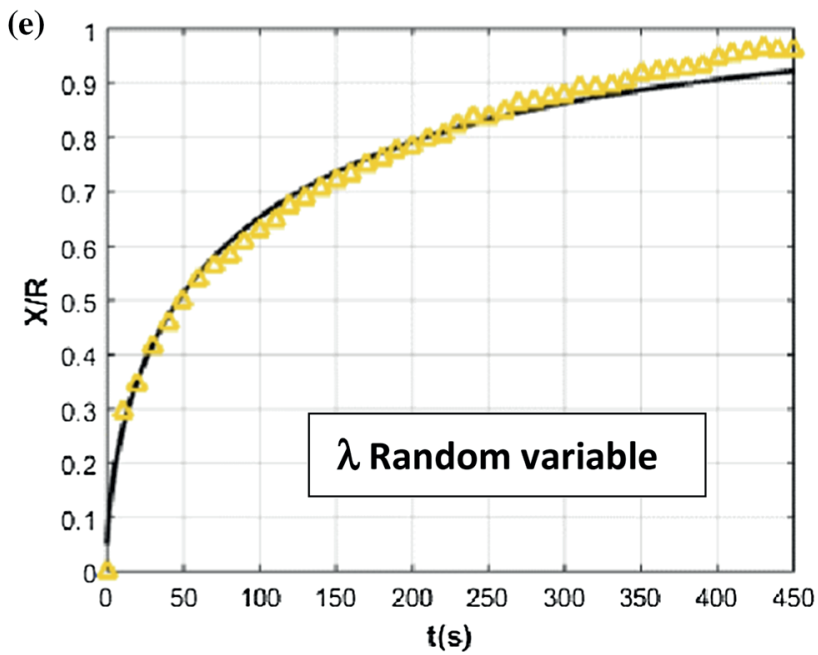

Figure 11 Results of the probabilistic coalescence model and comparison with the data (triangular marker): a pdf of the random variable $\eta, \mathbf{b}$ random trials of $\eta$ according to its pdf, $\mathbf{c}$ probabilistic numerical coalescence ( $\eta$ random), d probabilistic numerical coalescence $\left(a_{0}\right.$ random), e probabilistic numerical coalescence $(\lambda$ random). 


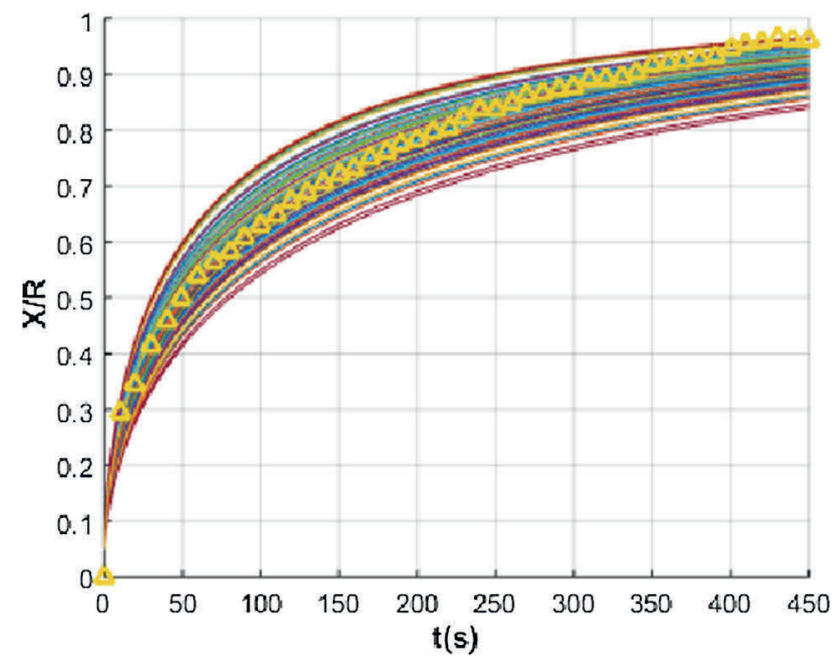

Figure 12 Results of the probabilistic coalescence model $(\eta, \Gamma$ and $a_{0}$ are simultaneously random).

experimental data and the probabilistic numerical model was nearly $11 \%$.

\section{Conclusion}

In this research, a numerical model based on the Bellehumeur approach is suggested to predict the coalescence phenomenon between two particles derived from different polymers. This model aims to generalize the Bellehumeur relation commonly used to describe the coalescence between identical grains to the case of different polymers. The predictive model was assessed by suggesting equations system resolution and by postulating modified mixture laws which relates the properties of each polymer (surface tension, viscosity and relaxation time) in order to identify and optimize the equivalent rheological and physical properties of the coalescence domain. The results of the suggested model have shown a good correlation with the experimental data. In addition, in the light of the experimental uncertainties derived from the experimental part, a probabilistic analysis was presented in order to investigate the sensitivity of the predictive approach with regard to the model governing parameters (viscosity $\eta$, surface tension coefficient $\Gamma$, relaxation time $\lambda$ and grains radius $a_{0}$ ). For this purpose, based on the statistical available information gathered from the experimental work, adequate probabilistic density functions (pdf) were constructed for the different random variables associated with the uncertain parameters. The results of the probabilistic model have shown that unlike the relaxation time, the suggested model is rather influenced by $\Gamma, \eta$ and $a_{0}$.

In the future, it would be of interest to use the suggested predictive model for other polymer pairs, in order to investigate its adaptability to other materials. Moreover, work is now in progress in order to study the densification phenomenon between PVDF and PMMA particles based on the Bellehumeur generalized model proposed in the present work. The objective of the densification modeling is the evaluation of the porosity of the final polymer obtained during a rotational molding process. This task is an important challenge governing the end properties of the final product and allowing thereby the optimization of the molding cycle time [17].

\section{Acknowledgement}

The authors would like to acknowledge the financial support of the Chaire Mines Urbaines and Marianne Fleury from Ecosystèmes (France).

\section{References}

[1] Bellehumeur CT, Bisaria MK, Vlachopoulos J (1996) An experimental study and model assessment of polymer sintering. Polym Eng Sci 36:2198-2207. doi:10.1002/pen. 10617

[2] Bellehumeur CT, Kontopoulou M, Vlachopoulos J (1998) The role of viscoelasticity in polymer sintering. Rheol Acta 37:270-278. doi:10.1007/s003970050114

[3] Bellehumeur CT (1997) Polymer sintering and its role in rotational molding. Thesis

[4] Rosenzweig N, Narkis M (1981) Sintering rheology of amorphous polymers. Polym Eng Sci 21:1167-1170. doi:10. 1002/pen.760211709

[5] Kuczynski GC, Neuville B, Toner HP (1970) Study of sintering of poly(methyl methacrylate). J Appl Polym Sci 14:2069-2077. doi:10.1002/app.1970.070140815

[6] Rosenzweig N, Narkis M (1981) Observation and analysis technique for studying sintering of polymeric particles. J Appl Polym Sci 26:2787-2789. doi:10.1002/app.1981. 070260828

[7] Hornsby PR, Maxwell AS (1992) Mechanism of sintering between polypropylene beads. J Mater Sci 27:2525-2533. doi:10.1007/BF01105065 
[8] Aid S, Eddhahak A, Ortega Z et al (2017) Experimental study of the miscibility of ABS/PC polymer blends and investigation of the processing effect. J Appl Polym Sci. doi:10.1002/app.44975

[9] Frenkel J (1945) Viscous flow of crystalline bodies under the action of surface tension. J Phys 4:385-431

[10] Rosenzweig N, Narkis M (1981) Dimensional variations of two spherical polymeric particles during sintering. Polym Eng Sci 21:582-585. doi:10.1002/pen.760211003

[11] Pokluda O, Bellehumeur CT, Vlachopoulos J (1997) Modification of Frenkel's model for sintering. AIChE J 43:32533256. doi:10.1002/aic.690431213

[12] Ramos JI, Joseph DD (1991) Fluid dynamics of viscoelastic liquids. Appl Math Model 15:662-663

[13] Asgarpour M, Bakir F, Khelladi S et al (2011) Characterization and modeling of sintering of polymer particles. J Appl Polym Sci 119:2784-2792. doi:10.1002/app.32924
[14] Hamidi A, Farzaneh S, Nony F et al (2016) Modelling of sintering during rotational moulding of the thermoplastic polymers. Int J Mater Form 9:519-530. doi:10.1007/s12289015-1239-6

[15] Andreas JM, Hauser EA, Tucker WB (1937) Boundary tension by pendant drops 1 . J Phys Chem 42:1001-1019. doi: $10.1021 / \mathrm{j} 100903 \mathrm{a} 002$

[16] Jaynes ET (1957) Information theory and statistical mechanics. Phys Rev 106:620-630. doi:10.1103/PhysRev.106.620

[17] Bellehumeur CT, Tiang JS (2002) Simulation of non-isothermal melt densification of polyethylene in rotational molding. Polym Eng Sci 42:215-229. doi:10.1002/pen.10942 